Text Interpretation as a Scientific Activity

C. Mantzavinos

Published in: Journal for General Philosophy of Science, vol. 45, 2014, pp. $45-58$. 


\title{
Text Interpretation as a Scientific Activity
}

\section{Mantzavinos}

\begin{abstract}
One way to show that text interpretation can be treated as a scientific problem is to show that the standards that are currently used in the natural sciences when dealing with problems not involving meaningful material can also be successfully employed in the case of text interpretation. These standards involve (but are not confined to) intersubjective intelligibility, testability with the use of evidence, rational argumentation, and making methodological decisions aiming at the attainment of truth, accuracy, simplicity and other epistemic values. In the case of text interpretation - despite the fact that we deal with meaningful material hypotheses can be formulated, consequences can be drawn by deduction, and these can be tested against empirical data. This claim is substantiated by the provision of an exampl of a scientific text.
\end{abstract}

Keywords: Hermeneutics; Hypothetico-Deductive Method; Text Interpretation 
1. Introduction. According to a common view human actions are meaningful ${ }^{\mathrm{a}}$ and texts and other by-products of human action constitute meaningful material. Text interpretation is a problem that lay-people and scientists alike are called to deal with in their everyday practices and the fundamental issue is both to accurately describe these activities and to normatively appraise them. In the last decades, one major line of thought which I want to label «postmodernist» has dominated the discussion, according to which text interpretation is not a problem that can be treated scientifically, i.e. using any of the standards employed in the natural sciences. Philosophical hermeneutics in the tradition of Heidegger and Gadamer and deconstructionism in the tradition of Derrida have challenged the possibility of achieving any kind of hermeneutic objectivity, of distinguishing between correct and incorrect interpretations and of appealing to any kind of evidential support of different interpretative hypotheses.

Analytical philosophy of science has - with very few exceptions - systematically avoided the treatment of the concrete problems that emerge when dealing with meaningful material, so that literally no attention is paid to a great range of disciplines that deal with text interpretation. All those disciplines, summarized under the collective term "Humanities," are practically excluded from the endeavours of philosophers of science, largely because there is a hesitance to reconstruct and normatively appraise their activities employing the standard tools of the analytic philosophy of science, most importantly the analysis of the relationship between theory and evidence.

Rather than providing a criticism of the great array of «postmodernist» approaches, the aim of this essay is positive: it attempts to show that the problem of text interpretation can be dealt with in a way that respects the standards prevailing in the general philosophy of science. The

\footnotetext{
${ }^{\mathrm{a}}$ For a discussion of meaningful human actions see Mantzavinos (2012).
} 
thrust of the argument is that one way to approach and solve the problem of text interpretation is to employ the hypothetico-deductive method, which is construed very broadly.

2. The Hypothetico-Deductive Method: Some Clarifications. Demarcating an activity as 'scientific' or alternatively, and more traditionally, characterizing the products of an activity as 'scientific' is a notoriously hard problem which is not to be dealt with in this essay. My modest aim will be instead to show that the standards that are currently used in the natural sciences when dealing with problems not involving meaningful material can also be successfully employed in the case of text interpretation. These standards involve (but are not confined to) intersubjective intelligibility, testability with the use of evidence, rational argumentation, and making methodological decisions aiming at the attainment of truth, accuracy, simplicity and other epistemic values. All of these standards are involved when the hypothetico-deductive method is used.

Let me state clearly the essential characteristics of this method right at the beginning. Its first characteristic consists in viewing scientific work as being related to hypotheses: the propositions put forward in scientific work are viewed as fallible hypotheses instead of absolute certain propositions. The second essential characteristic of this method consists in the fact that the hypotheses are tested by deducing consequences from them and by checking how well these consequences fit in with our experience and our other beliefs supported by independent evidence. Even though the empirical data used in the humanities consist to a large degree of meaningful material, this does not render the process of testing the hypotheses impossible - though it can somehow complicate it.

I will provide a more systematic exposition of this method in the next section, but I would like to provide three clarifications at the outset. First, it has become common that the hypothetico- 
deductive method is treated as a confirmation theory and as such it has been the object of various attacks, some of them fair and relevant. ${ }^{1}$ However, I claim that this narrowing of the focus can be resisted and is indeed not necessary. The hypothetico-deductive method which I would like to defend here is rather a general framework within which to view scientific activity. My point is not that text interpretation could not be also understood as a scientific activity, more along the lines suggested by other views; this might be indeed the case. My point is rather this: One way to show that text interpretation can be treated as a scientific problem is to show that it can be treated adequately according to the precepts of scientific rationality encapsulated in the view of scientific activity as a process of formulating conjectures and testing them with the aid of empirical evidence. ${ }^{2}$ If one opts to conceptualize scientific rationality in this general way, then text interpretation can surely be viewed as a normal scientific activity.

Second, the hypothetico-deductive method has also been discussed in connection with explanatory activities, mainly in relation to the very influential model of the deductivenomological explanation (e.g. Popper 1959/2003 and 1963/1989). This has in turn given rise to the untenable claim that all theoretical scientific activity is exhausted in providing explanations of phenomena and laws - interpretative activities have been quasi-automatically excluded from this picture. Doing away with the bias of viewing all scientific activity as explanatory activity and allowing answers to "what was the case?"questions to enter the field of science seems an appropriate way to accommodate the activities of all those practising scientists whose daily work consists in text interpretation.

Third, the proposal that scientists in the natural sciences and in the humanities use the hypothetico-deductive method as it will be conceptualized here is not identical with Popperian falsificationism as a theory of scientific rationality. It merely points out that text interpreters 
often test their hypotheses by deriving testable claims from them and comparing them with empirical data. The paper thus aims at a description of scientific practice and my argument is that scholars working on the interpretation of texts follow a general practice also followed by scholars working in other areas. The normative aspect of my argument consists in showing that the use of the hypothetico-method is possible with respect to meaningful material, so that it can be used by scholars engaged in text interpretation.

3. "Why" questions and "What is the case" questions. There is a long tradition of theories of explanation in the analytical philosophy of science. ${ }^{3}$ The focus of attention, one way or another, has been on "Why" questions, the answering of which surely constitutes one central goal of theoretical science. However important the task of coming to grips with explanation as a main goal of scientific activity, it is definitely biased to portray all scientific activity as explanatory activity. If the activities of historians, philologists, archaeologists, etc. are not to be denied the honorific title "scientific", then another central goal should also be recognized: the identification of individual facts that answer questions of the type "what is the case?" or "what was the case?". The answers to questions of this type allege the existence of individual facts. They are singular descriptive sentences about individual events and are temporally and spatially determined. How should one deal with those kinds of questions, however? Is the hypothetico-deductive method applicable here as well, and if yes, how exactly? The answer is positive.

The usual scientific problem in the humanities is, thus, not best characterized as a search for an answer to a "why" question, but as attempting to answer a "what is the case" question or a "what was the case" question. The scientific problem consists in identifying individual facts, and thus in accurately determining a nexus of meaning that is connected with a specific linguistic expression or a specific text ${ }^{4}$. Linguistic expressions are bestowed with meaning 
when, in producing them, the author construes them against the background of his goals, his beliefs, and his other mental states while interacting with his natural and social environments; such a construal of meaning is a complex process, and it involves the conscious and unconscious use of symbols. The aim of identifying the nexus of meaning of a spoken or written expression can be reached with the help of interpretation.

Before proceeding, a couple of remarks seem appropriate. First, interpreting a text and higlighting its significance are two distinct activities. Interpretation, as we will see in a moment, is an activity that aims at ascertaining the meaning of a text, while textual criticism is an activity that is concerned with the significance of a text with respect to different goals and purposes. ${ }^{5}$ Second, interpreting a text and applying a text are also two distinct activities. In different disciplines there are very heterogeneous applications of textual content, depending upon the difference in the problems that those disciplines deal with (Bühler 1999a, p. 128f.). Thus, in applying a legal text in the field of jurisprudence one is concerned with regulating concrete social problems. The application of literary texts, on the other hand, consists in the reader's adoption of a particular view of life. In our context it is only important that, irrespective of how the application of textual content is thematized, this activity is not to be confounded with interpretation.

4. Text Interpretation and the Hypothetico-Deductive Method. It is now important to show how exactly the hypothetico-deductive method can be applied to the activity of text interpretation. Textual interpretation is about correctly identifying the meaning of a text. The scientific problem consists in accurately reconstructing the nexus of meaning that has arisen in connection with the text to be interpreted. The nexus of meaning can be reconstructed either by indicating the author's intention (Grice 1989; Hermerén, 1975) or by applying some principles of rationality (Livingston 1993), and these are in fact the descriptive systems that 
are often used in everyday research. In principle, however, reconstructions can be carried out with the most diverse conceptual apparatuses, and therefore the nexus of meaning of a text can be expressed by quite diverse natural or artificial linguistic means (Kintsch and van Dijk 1978; Kintsch 1998).

A. Because a text is bestowed with meaning when the author construes it against the background of his goals, his beliefs and his other mental states by means of symbols, the point is to identify this meaning by correctly reconstructing the fundamental elements of this nexus. In order to achieve this, one establishes interpretive hypotheses, and this is the first step in applying the hypothetico-deductive method. The system of propositions that constitutes these interpretive hypotheses is in principle hypothetical, because it is not certain whether it is apt to meet the epistemological goal or not, i.e. if it is apt to identify the meaning of the text.

It is important to stress that there are no particular algorithms underlying the process of formulating interpretive hypotheses that are to elicit the meaning of the text. In the discussion on what is known as "radical interpretation", one presupposes that the interpretation of written expressions must follow some specific interpretive principles. Quine $(1960,59)$ and Davidson (1984, 27) propose, for example, the "principle of charity" as the general interpretive principle, which is supposed to provide an imperative instrument for correct interpretation. In two of the most common versions, this principle requires that the interpreter assume that the conditions under which the author holds the sentence to be true are largely conditions under which these sentences are in fact true (the presumption of truth in general). Alternatively it requires that the interpreter presume that the sentences of the author are, in general, internally consistent and consistent with one another (presumption of consistency). Grandy (1973, 443) views the "principle of humanity" as a guide - that is, the requirement that the pattern of 
relations among beliefs, desires and the world ascribed to the author be as similar to our own patterns as possible.

The logical status of the "principle of charity", of the "principle of humanity" and of all the other principles of interpretation that were proposed in the older hermeneutic tradition or that are currently discussed in analytic philosophy of language ${ }^{6}$ remains largely unaddressed. But in general they are felt to be indispensable rules that must be used in every interpretation that strives to be correct. Regardless of whether these principles are indispensable, they are in any case to be viewed as presumptive rules, i.e. as empirical rules that can fail to stand up to experience. So, every presumption can break down in the light of experience. Whether the usage of those presumptive rules is constitutive for the practice of interpretation can be left undecided. It seems to me in any case that the appearance that they are indispensable is to be traced to the fact that they have been employed with success. It is thus only their higher degree of corroboration (or higher degree of confirmation depending on the confirmation theory that one favors) that disposes one to presume that they are indispensable for every interpretation.

B. The interpretive hypotheses might not consist of purely observable terms or to put it in another way they might not refer to observable entities, exactly as it is the case in the natural sciences. Very often interpretive hypotheses consist of statements about the intention of the author, for example, which is surely nothing directly observable. The second step of the application of the method is relevant here: one can deduce from such interpretive hypotheses in conjunction with other statements consequences which are (more) observable. For example, from a hypothesis about the intention of the author one can deduce some features that should be expected in the text. Such observable consequences can normally be formulated when the interpretative hypothesis is embedded in a larger theoretical context, i.e. when one or more 
auxiliary hypotheses are employed. In the natural sciences these auxiliary hypotheses include everyday knowledge, theories about observation, measurement theories etc. In the case of interpretation these auxiliary hypotheses will include everyday knowledge, genre theory, stylistic theory etc. These auxiliary hypotheses should be acceptable on grounds other than the concrete test-situation, i.e. they should not be introduced in an ad hoc way. This requires a methodological decision about their acceptability. Such a decision cannot be taken following any specific algorithm - even if it were possible to construct such algorithms, one would again be confronted with a choice of the appropriate algorithm. Thus, a genuine decision of a methodological nature is important here and the quality of the decision will depend on the quality of the critical discussion which will inform it. Such a discussion can take place among the interpreters themselves and the philosophers of science alike along the lines that I will indicate later, under E.

C. After the interpretive hypotheses are formulated, and observable consequences are drawn from them with the use of deduction, they must be empirically tested - this is the third step of the application of the method. They are tested on the basis of the available evidence, which is primarily made accessible with the help of research techniques from the social sciences and the humanities. This evidence can be drawn from what the author says about his own work, but it can also encompass anything else that the author has ever written. Besides that, the details of rhyme, rhythm or other literary stylistic means can be taken into consideration, as can the frequency with which words occur in the text and similar such evidence. In any case it is important to emphasize that in listing the various features that are supposed to support the respective interpretive hypothesis, it is not only the number of features that is important; so are the type of features that we are dealing with. ${ }^{7}$ 
D. Let us proceed with the fourth step of application of the method. On the basis of such empirical material the interpretative hypotheses are checked; the question then arises concerning how good interpretations are to be differentiated from bad ones ${ }^{8}$. The concern in these interpretive hypotheses, as has already been emphasized, is with correctly depicting the nexus of meaning that has arisen with a given text. Like every other scientific activity, interpretation can also be characterized as an enterprise that can in principle be oriented on the idea of truth. In the case of interpretation, truth, as the accurate depiction of facts, can also serve as a regulative idea, on the basis of which interpretive hypotheses can be evaluated. Interpretations, as reconstructions of nexuses of meaning, are hypotheses precisely by virtue of the fact that one searches for reasons for their truth or falsity. The various reconstructions of nexuses of meaning offered are to be compared to each other with regard to their truth, and those to be preferred that most accurately reconstruct the respective nexuses of meaning.

The comparative evaluation of interpretive hypotheses can be also oriented on other regulative ideals. Besides the assessment of the interpretive hypotheses about the meaning of a text in relation to the idea of truth, it is, of course, possible to interpret a text in reference to other ideals - for example, aesthetic ones. This is a common claim among literary theorists, a claim that is both plausible and correct. The same set of interpretations can be evaluated with respect to different ideals (such as beauty for example) and found to be fulfilling some of them while not fulfilling others. An interpretation can be, for example, original but at the same time false. My modest claim here is that one of the regulative ideas towards which text interpretation can be oriented is truth and other epistemic values also prevalent in the natural sciences; and as long as this is the case, then text interpretation constitutes a scientific activity.

E. It is important to stress that evaluation is always a comparative matter, i.e. there are typically more interpretive hypotheses that are evaluated on the basis of the available data 
with respect to different values. A multi-dimensional evaluation of the same hypothesis with respect to different values or of a set of hypothesis with respect to one value is naturally possible - this is undertaken in the fifth step of the application of the hypothetico-deductive method. Decades of discussion after the heyday of logical positivism in the analytic philosophy of science have brought to light the impossibility of unequivocally making supposedly rational decisions about the validity of scientific knowledge by applying specific algorithms. Such decisions are naturally problematic also in the case of the evaluation of interpretations of texts with respect to different values. Constructing algorithms and sometimes even calculi designed to replace controversies with calculations is a futile enterprise. Basing scientific and more specifically interpretive methodology merely on the interplay of logic and evidence is surely insufficient, since it unduly brackets the role of imagination in the cognitive praxis and probably most importantly the role of choice.

It is exactly at this point that the framework that I propose decisively differs from the classic hypothetico-deductive method of confirmation which misses this point. As it is well-known, this classic model of confirmation has a capital weakness (among others, less serious ones). If contingent evidence $\mathrm{E}$ confirms hypothesis $\mathrm{H}$ given background beliefs $\mathrm{B}$, then $\mathrm{E}$ confirms also the conjunction $\mathrm{H}^{\wedge} \mathrm{X}$ for any arbitrary $\mathrm{X}$ consistent with $\mathrm{H}$. In other words, if an observable consequence $\mathrm{e}$ is deducible from a hypothesis $\mathrm{H}$ (and some background assumptions), then e is also deducible from any arbitrary set of assumptions in conjunction with $\mathrm{H}$, for example $\mathrm{H}^{\wedge} \mathrm{X}$. Then it is also logically valid that: if e conforms with the evidence $\mathrm{E}$ and therefore it confirms $\mathrm{H}$, then e also confirms $\mathrm{H}^{\wedge} \mathrm{X}$. This means that $\mathrm{X}$ which, as already mentioned, can be completely arbitrary and as regards its content in no connection with $\mathrm{H}$, would also be supported by $\mathrm{E}$. 
Scholz (2014) calls this the 'relevance problem' and suggests that it be solved by employing an inference to the best explanation. In other words, given that the deductive part of the hypothetico-deductive method in its version as a purely confirmation method is problematic by being extremely permissive, the concrete proposal is to substitute it with an inference to the best explanation (Lipton, 2004): from the interpretative hypotheses offered, the one should be accepted which better explains the evidence. However, this move is also problematic; it is based on the assumptions that (i) there is a precise answer to the question "what is an explanation? and that (ii) there is a clear-cut, universally acceptable normative account of what constitutes the 'best explanation' - both assumptions are, however, untenable (Mantzavinos, 2013). The proposal of substituting a deductive rule with another kind of inferential rule purports to establish what seems to be still a kind of an algorithm escaping the necessity of making genuine methodological choices.

Creative decisions, i.e. human decisions by real-world human beings, are, however, permanently involved in all stages of the process of comparative evaluation of alternative interpretive hypotheses. Dethroning Olympian rationality as an impossible ideal does not necessarily lead to irrationalism or relativism, however. The rationality of the proposed interpretative methodology does not lie in the proof or defense of a specific algorithm or justificatory procedure as the most adequate one to establish the validity of an interpretation. The rationality lies instead in laying the ground for the criticism of the diverse interpretive hypotheses. This is a procedural rationality that I would like to defend here, which does not prescribe the content of the decisions which are ultimately taken by the participants of the discussion about the appropriate reconstructions of specific nexuses of meaning themselves, but highlights instead the individual and collective conditions that must prevail in order for these decisions and judgments to be informed and adequate with respect to the goals and values that they are aiming at. 
Of course, the outcomes of these decisions are themselves fallible. As with all problemsolving activities and even more so in the case of choice, errors are possible and common. Institutionalizing the possibility of criticism is the best means to facilitate the correction of errors when choices are involved. The anchoring of the freedom of criticism in the institutional framework of the society is the broader collective condition that must prevail and enables procedural rationality to manifest itself ${ }^{9}$. Our fallible judgments are all what we have here as elsewhere and enabling a critical discussion is the prerequisite of making informed choices about which interpretive hypotheses to provisionally adopt. And it is important to stress again that there is no algorithm relieving us from the necessity to make the choices. Controversies cannot be substituted by calculations - we still have to form judgments and decide which calculations to adopt.

All we avail of is the possibility of participating to the critical discussion and the possibility of framing informed judgments about these issues and defending them with arguments. My modest claim here is that appeals to empirical evidence of very different sorts do and can play the role of important and reliable arguments in favor of specific hypotheses in actual discourses, that these arguments are intersubjectively intelligible and that they can help establish hermeneutic objectivity - to the degree that this is the case, my claim is that text interpretation can be viewed as a normal scientific activity.

In order to substantiate my claim, I would like to provide an example of an evaluation with respect to truth, understood as an accurate reconstruction of a nexus of meaning. This is especially important, I think, since other than the interpretation of Ibsen`s Peer Gynt that Føllesdal (1979) provides and the interpretation of a poem by Sappho that Detel (2011, p. 
394ff.) offers, there is nearly no other example in the literature on how text interpretation can be conceptualized as an activity oriented to the regulative idea of truth.

5. The Invisible Hand. I will discuss a case from a scientific work, more specifically, the interpretation of the invisible hand in Adam Smith's work An Inquiry Into The Nature and Causes of The Wealth of Nations (1776/1976). The invisible hand has been salient in the discussions in the social science ${ }^{10}$ as mentioned in Book IV, Ch. II of this classic (477f.):

"But the annual revenue of every society is always precisely equal to the exchangeable value of the whole annual produce of its industry, or rather is precisely the same thing with that exchangeable value. As every individual, therefore, endeavours as much as he can both to employ his capital in the support of domestic industry, and so to direct that industry that its produce may be of the greatest value; every individual necessarily labours to render the annual revenue of the society as great as he can. He generally, indeed, neither intends to promote the public interest, nor knows how much he is promoting it. By preferring the support of domestic to that of foreign industry, he intends only his own security; and by directing that industry in such a manner as its produce may be of the greatest value, he intends only his own gain, and he is in this, as in many other cases, led by an invisible hand to promote an end which was no part of his intention."

There are three main interpretations of this passage which have been proposed in the discussions of many scholars in the twentieth century focusing on the meaning of the invisible hand: 
I. The standard interpretation aiming at the reconstruction of the nexus of meaning of this passage referring to the invisible hand, which is usually found in most histories of economic thought and that most students of markets and political systems seem to endorse is the following: a society of self-interested people constrained by criminal law and the law of property and contract is capable of an orderly disposition of its economic resources; such a society need not be anarchic and is indeed coherent with order (Hahn, 1982, p. 1). The order of the economic system of such a society is usually conceptualized as a system of a general equilibrium that can be shown to prevail in an economic system, if a series of assumptions are made.

The evidence used in order to support this specific reconstruction of the nexus of meaning of this specific passage is usually drawn from the general argument of Adam Smith's book concerning the merits of "the obvious and simple system of natural liberty" (Bk. IV, Ch. IX, p. 208) as well as his elaboration on the theory of price (Bk. I, most importantly Ch. VII). Further evidence in support of this standard interpretation is drawn from another famous passage to be found in his other major work The Theory of Moral Sentiments (1759/1976, p. 184):

"The capacity of [the proud and unfeeling landlord's] stomach bears no proportion to the immensity of his desires, and will receive no more than that of the meanest peasant. The rest he is obliged to distribute among those, who prepare, in the nicest manner, that little which he makes use of, among those who fit up the palace in which this little is to be consumed, among those who provide and keep in order all the different baubles and trinkets which are employed in the economy of greatness; all of whom thus derive from his luxury and caprice, that share of the necessaries of life which they would in vain have expected from his humanity or his justice. The produce 
of the soil maintains at all times nearly that number of inhabitants which it is capable of maintaining. The rich only select from the heap what is most precious and agreeable. They consume little more than the poor, and in spite of their natural selfishness and rapacity, though they mean only their own conveniency, though the sole end which they propose from the labours of all the thousands whom they employ, be the gratification of their own vain and insatiable desires, they divide with the poor the produce of all their improvements. They are led by an invisible hand to make nearly the same distribution of the necessaries of life, which would have been made, had the earth been divided into equal portions among all its inhabitants, and thus without intending it, without knowing it, advance the interest of the society, and afford means to the multiplication of the species."

Lastly, further supoort of the standard interpretation of the invisible hand is drawn from the analysis of works of other authors of the Scottish Enlightenment who held similar views and from the analysis of the ideas of the so-called Physiocrats which seem to have dominated France in the eighteenth century.

II. Attention to a third locus in the Smithian work where the invisible hand is mentioned was first drawn by Alec Macfie (1971): Adam Smith in a section dealing with the "Origins of Philosophy" in his History of Astronomy, originally published in the Essays on Philosophical Subjects (1795/1980), refers to the savage "in the first ages of society" (p. 48) and remarks (p.49):

"With him, therefore, every object of nature, which by its beauty or greatness, its utility or hurtfulness, is considerable enough to attract his attention, and whose operations are not perfectly regular, is supposed to act by the direction of some 
invisible and designing power. [...] Hence the origin of Polytheism, and of that vulgar superstition which ascribes all the irregular events of nature to the favour or displeasure of intelligent, though invisible beings, to gods, daemons, witches, genii, fairies. For it may be observed, that in all Polytheistic religions, among savages, as well as in the early ages of Heathen antiquity, it is the irregular events of nature only that are ascribed to the agency and power of their gods. Fire burns, and water refreshes; heavy bodies descend, and lighter substances fly upwards, by the necessity of their own nature; nor was the invisible hand of Jupiter ever apprehended to be employed in those matters. But thunder and lightning, storms and sunshine, those more irregular events were ascribed to his favour, or his anger. Man, the only designing power with which they were acquainted, never acts but either to stop, or to alter the course, which natural events would take, if left to themselves. Those other intelligent beings, whom they imagined, but knew not, were naturally supposed to act in the same manner; not to employ themselves in supporting the ordinary course of things, which went on of its own accord, but to stop, to thwart, and to disturb it."

The function of the "invisible hand of Jupiter" in the History of Astronomy appears to be exactly the reverse than of the Christian Deity of the Moral Sentiments and the Wealth of Nations as Macfie observes (p. 595):

“In the Essay, the regular 'orderly course of things' by which 'fire burns and water refreshes' is capriciously stopped, thwarted, and disturbed so as to satisfy the god's 'favour' or 'anger'. In the two books, on the contrary, the Deity acts to preserve and develop the purposes of 'Nature' when they are disturbed by men - the only other 'designing power' which, in Smith's description (the 'savage' here, but obviously men at any time) can disturb them." 
It seems, thus, that there is a new piece of evidence, that is, a passage of another work of the same author where the meaning of the invisible hand seems to be a different one. The scientific problem consists in accurately reconstructing the nexus of the meaning that has arisen in connection with the notion of the invisible hand in the Wealth of Nations; MacFie establishes the following interpretive hypothesis with the help of the use of the principle of charity (p. 596):

"Perhaps it should be stated here that while the capricious role of the 'invisible hand of Jupiter' is quite different from that of the order-preserving 'invisible hand' in the two books, there is no inconsistency. The explanation is the view of history typical of the Enlightenment. In the Essay Jupiter represents the ignorant 'savage's' view, long before the seventeenth- and eighteenth-century understanding of the divine order, mainly preserved through social individuals, had been worked out. The invisible hand passages of the two books in fact describe Adam Smith's interpretation of how the natural order of 'providence' animates and directs the orderly development of these societies (as well, of course, as the physical universe). One is reminded of the first and third ages of Vico - the age of the gods and the age of men. But similar interpretations of history were common in the Scottish eighteenth-century school."

This interpretive hypothesis is constructed following the principle of charity and this is important to note: the interpreter, MacFie, presumes that the sentences of the author, Adam Smith, are in general internally consistent and consistent with one another. This allows him to present a hypothesis concerning the invisible hand that provides a unitary, consistent interpretation and makes a number of different and specific features of the work all appear fitting. 
III. According to a third, novel interpretative hypothesis of the invisible hand proposed by Emma Rothschild (1994, p. 329), Adam Smith did not particularly esteem the invisible hand and thought of it as an ironic though useful joke. The reconstruction of the nexus of meaning proposed by Rothschild (1994, 2002 ch.5) draws on four sorts of evidence:

(i) "One reason to suspect that Smith was not entirely enthusiastic about theories of the invisible hand is that these theories are condescending or contemptuous about the intentions of individual agents. Smith's three uses of the phrase have in common that the individuals concerned are quite undignified; they are silly polytheists, rapacious proprietors, disingenuous merchants." (1994, p. 320)

Smith was known to be a defender of individual liberty and of the independence of individuals. For such an author such an account of the invisible hand seems to be contradictory, if seriously meant. (ii) The invisible hand presupposes the existence of a theorist who can view what the rest cannot; this knowingness of the theorist is characteristic of eighteenth- and nineteenth-century doctrines of unintended consequences but is quite unlike Adam Smith. (iii) Smith was in fact quite critical of established religion. The comments on religion in his opus, like those of Hume, are conscious of pious public opinion, but also ironical. Given that, the invisible hand should not be viewed as a way of expressing Smith's religious beliefs, i.e. as the hand of the Christian deity (apparently consistent with deism). If one considers other passages in his work, one can find that they are also ironical rather than pious, as when he for example speaks of the 
"all-wise Being, who directs all the movements of nature; and who is determined, by his own unalterable perfections, to maintain in it, at all times, the greatest possible quantity of happiness.” (Smith, 1759/1976, p.235).

(iv) Central to the political economy of Smith were his criticisms of government and institutions. He has himself proposed an institutional design for consciously influencing the economic life of a nation by way of appropriate political institutions. So, it is rather improbable and in fact quite inconsistent that he would simply neglect or just forget this when discussing the advantages of the functioning of an invisible hand.

Rothschild's interpretive hypothesis, thus, based on different sorts of evidence, provides an interpretation of the invisible hand that is contrary to the standard interpretation and different from the interpretation of Macfie.

The comparative evaluation of the three interpretive hypotheses can occur with respect to different regulative ideals. We will concentrate here on their comparative evaluation with respect to truth.

All three hypotheses are based on deductions of a number of consequences from them that, along with other empirical evidence, are shown to fit with the passage of the invisible hand in the Wealth of Nations. The standard interpretation is founded on solid empirical evidence from a variety of sources, since evidence is called upon not only from other similar passages of the same author but also from other authors and from the intellectual environment that Smith was part of. 
The interpretation of MacFie considers only three passages in which Smith mentions the invisible hand. He deduces from its use in the Wealth of Nations and in the Theory of Moral Sentiments, along with the premise that Smith endorsed Deism, the consequence that the function of the invisible hand was to preserve the purposes of "Nature" in the social realm and thus to help bring order into a society of self-interested individuals. From the use of the "invisible hand of Jupiter" in the Essay, along with the premise that the lecture notes on which the Essay was based stem from his juvenile work (MacFie, 1971, p. 598), he draws the conclusion that the function of the invisible hand was not to maintain order, but rather to disturb it according to god's "favour" and "anger". This is an evident contradiction and in order to eliminate it, MacFie proposes that the change in the role for the invisible hand is a matter of literary taste. "Throughout his works, Smith employed and enjoyed pithy, forceful phrases" and simply "remembered the 'invisible hand of Jupiter' [b]ut he inevitably reversed its relation to the natural order". (p. 598) However, this is not supported by further evidence or arguments and is not convincing. Taking also into consideration that only the three passages are used as evidence and not a broader array of empirical material, it seems that this interpretation is the least valid of the three.

Rothschild's interpretation is supported by solid evidence based on the consideration of a large amount of relevant material. On the other hand, it seems to be the case that there is something crucial that is not adequately considered by Rothschild. In the passage of the Wealth of Nations one very important sentence is the following: "By pursuing his own interest he frequently promotes that of the society more effectually than when he really intends to promote it." [emphasis added] This seems to weaken the evidence Rothschild referred to especially under (i) and (iv). 
The provisional conclusion can be drawn, that the second interpretation is to be disregarded and that there is enough evidence to support both the standard interpretation and the interpretation of Rothschild. As is common in science, the empirical evidence does not allow one in this case to make a decision and clearly favor one interpretive hypothesis. The stance to be adopted is to abstain from a judgment regarding the truth of the respective hypotheses. The critical discussion might enable a more informed decision in the future.

6. Conclusion. Text interpretation can be conceptualized and practiced like every other scientific activity: hypotheses are generated and they are tested on the basis of evidence. Generating hypotheses is normally a creative act, which, precisely like the generation of other scientific hypotheses, hardly follows an algorithm: there is no procedure, no specific principle that necessarily leads to the generation of a correct interpretation of a text. Interpretive hypotheses, however, can be evaluated on the basis of evidence, and fitting reconstructions of the nexus of meaning of the text can be differentiated from unfitting reconstructions. Interpretation can be conceptualized as a scientific process of reconstructing nexuses of meaning that can be oriented on the idea of truth; this is the exact opposite of a process of deconstruction, i.e. of interpretatively dissolving any and every text into a plurality of supposedly merit-equivalent constructions.

\section{Notes}


${ }^{1}$ This is not the place to review the arguments in the debate or to adjudicate the various disputes regarding the
appropriate theory of confirmation. For a discussion see Park (2004) and Gemes (2005). For particularly enlightening recent textbook discussions see Barker and Kitcher (2014, p. 25ff) and Schurz (2014, pp. 314ff).

${ }^{2}$ This is a minimalistic requirement which can be stated even for such disparate a field as literary studies. Schmidt (2000), for example, argues in a similar vein portraying the academic practices of literary scholars as problem-solving activities which must meet the usual standards of science.

${ }^{3}$ For a review see Mantzavinos (2015).

${ }^{4}$ I am deliberately using the term 'nexus of meaning' as a terminus technicus since this is the translation of 'Sinnzusammenhang', the term originally used by Dilthey and others in the traditon of classical hermeneutics (rather than philosophical hermeneutics).

${ }^{5}$ See Hirsch's fitting commentary $(1967,7 f$.$) , who has rightly insisted on the distinction between meaning and$ significance: "Probably the most extreme examples of this phenomenon are cases of authorial self-repudiation, such as Arnold's public attack on his masterpiece, Empedocles on Etna, or Schelling's rejection of all the philosophy he had written before 1809 . In these cases there cannot be the slightest doubt that the author's later response to his work was quite different from his original response. Instead of seeming beautiful, profound, or brilliant, the work seemed misguided, trivial, and false, and its meaning was no longer one that the author wished to convey. However, these examples do not show that the meaning of the work had changed, but precisely the opposite. If the work's meaning had changed (instead of the author himself and his attitudes), then the author would not have needed to repudiate his meaning and could have spared himself the discomfort of a public recantation. No doubt the significance of the work to the author had changed a great deal, but its meaning had not changed at all."

${ }^{6}$ Bühler (1987) discusses interpretive maxims as technological rules for achieving knowledge. See also the thorough discussion of the issue by Scholz (2001, p. 17ff.; 2004, p. 156ff. and 2009, p. 179ff.). See also Sinclair (2002) for a discussion of the radical interpretation from a naturalistic perspective.

${ }^{7}$ For more on evidence in the establishment of inerpretive hypotheses see the still relevant study by Gomperz (1939, 59ff.). See also Føllesdal (1979, 327): “[W]hen one interprets a text [...] one proceeds hypotheticodeductively. We set forth an hypothesis concerning the text or possibly the work as a whole and test this hypothesis by checking how its consequences fit in with the various details in the text. These details may be rhyme, rhythm and other literary devices. If, for example, a work is kept strictly in a rhythm that suddenly is broken, a satisfactory interpretation of the text, together with a stylistic theory of rhythm, should enable us to 
derive a conclusion which fits in with the break in the rhythm." And Rescher (1997, 200f.): "For text interpretation is clearly an evidential exercise where one has to make the best possible use of the relevant data over a wide range of information because a wide variety of hermeneutical factors must come into play:

-What the text itself explicitly affirms.

-Other relevant discussions by the author bearing on the issues that the text addresses.

-Biographical evidence regarding the author's education, interests, contacts, relevant interactions with contemporaries, and the like.

-Considerations of "intellectual history" regarding the state of knowledge and opinion in the author's place and time, and the cultural translation within which the text originated.

-Philological data regarding the use of terms and expressions in the time and place where the text was produced." ${ }^{8}$ In the tradition of classical hermeneutics of Schleiermacher (1999) and Dilthey (1883/1990; 1924/1990; 1927/1992) the possibility of establishing such claims has been explicitly or implicitly largely acknowledged only to be challenged again in the work of philosophical hermeneutics, more prominently by Gadamer (1960/1990; 1993; 2000), and by deconstructionism: any reader of a text establishes an interpretation of the text and one reader's interpretation is supposedly as good as another's, including the author's, according to this view. How problematic this view is, is brought excellently to the point in a very important article by Nehamas (1981, p. 140f.): 'Derrida argues that even the most obvious reading is the result of interpretation and can therefore be questioned, revised, or displaced. This is, I think, correct. Just as in scientific explanation there are no data immune to revision, so in literary criticism there are no readings impervious to question. But the fact about science does not show that apparently competing scientific theories are incommensurable and that therefore we cannot judge between them or that each such theory concerns its own distinct world. Similarly, the point about criticism does not show that different interpretations of a text are, even if apparently incompatible, equally acceptable or that a text has as many meanings as there are interpretations of it. Readings are neither arbitrary nor self-validating simply because they are all subject to revision. Newer readings are always guided by the strengths and weaknesses of those which already exist; and though this process may never stop, it is not for that very reason blind.'

${ }^{9}$ For a theory of the emergence and functioning of the institutional framework of a society see Mantzavinos (2001, part II). How the institutional framework enables and channels critical inquiry (in the context of a theory of explanation) see Mantzavinos (2014).

${ }^{10}$ The discussion of the example draws freely from Mantzavinos (2005, ch. 6.4). 


\section{References}

Barker, Gillian and Philip Kitcher (2014): Philosophy of Science. A New Introduction, New York and Oxford: Oxford University Press.

Bühler, Axel. 1987. "Die Einheit der wissenschaftlichen Methode und Maximen des Verstehens". Zeitschrift für philosophische Forschung 41: 633-644.

Bühler, Axel. 1999a. "Die Vielfalt des Interpretierens". Analyse und Kritik 21: 117-137.

Davidson, Donald. 1984. Inquiries into Truth and Interpretation. Oxford: Clarendon Press.

Detel, Wolfgang. 2011. Geist und Verstehen. Frankfurt am Main: Vittorio Klostermann.

Dilthey, Wilhelm (1883/1990): Gesammelte Schriften, I. Band: Einleitung in die Geisteswissenschaften, 9. Auflage, Stuttgart: B.G. Teubner Verlagsgesellschaft und Göttingen: Vandenhoeck \& Ruprecht.

Dilthey, Wilhelm (1924/1990): Gesammelte Schriften V. Band: Die geistige Welt. Einleitung in die Philosophie des Lebens. Erste Hälfte: Abhandlungen zur Grundlegung der Geisteswissenschaften, 8. Auflage, Stuttgart: B.G. Teubner Verlagsgesellschaft und Göttingen: Vandenhoeck \& Ruprecht. 
Dilthey, Wilhelm (1927/1992): Gesammelte Schriften VII. Band: Der Aufbau der geschichtlichen Welt in den Geisteswissenschaften, 8. unv. Auflage, Stuttgart: B.G. Teubner Verlagsgesellschaft und Göttingen: Vandenhoeck \& Ruprecht.

Føllesdal, Dagfinn. 1979. "Hermeneutics and the hypothetico-deductive method". Dialectica 33: 319-336.

Gadamer, Hans-Georg (1960/1990): Gesammelte Werke, Bd. 1, Hermeneutik I: Wahrheit und Methode, 6. Auflage, Tübingen: J.C.B. Mohr (Paul Siebeck).

Gadamer, Hans-Georg (1986/1993): Gesammelte Werke, Bd. 2, Hermeneutik II: Wahrheit und Methode, Ergänzungen, Register, 2. Auflage, Tübingen, J.C.B. Mohr (Paul Siebeck).

Gadamer, Hans-Georg (2000): Hermeneutische Entwürfe. Tübingen: J.C.B. Mohr (Paul Siebeck).

Gemes, Ken. 2005. “Hypothetico-Deductivism: Incomplete but not Hopeless”. Erkenntnis 63: 139-147.

Gomperz, Heinrich. 1939. Interpretation. Logical Analysis of a Method of Historical Research, Chicago: The University of Chicago Press.

Grandy, Richard. 1973. "Reference, Meaning and Belief”. Journal of Philosophy 70: 439-452.

Grice, Paul. 1989. Studies in the Way of Words. Cambridge, MA: Harvard University Press. 
Hahn, Frank. 1982. "Reflections on the Invisible Hand”. Lloyds Bank Review, 144: 1-21.

Hempel, Carl G. 1965. Aspects of Scientific Explanation and other Essays in the Philosophy of Science. New York: The Free Press.

Hermerén, Göran. 1975/76. "Intention and Interpretation in Literary Criticism”. New Literary History 7: 57-82.

Hirsch, Eric D. Jr. 1967. Validity in Interpretation. New Haven and London: Yale University Press.

Kintsch, Walter and Teun A. van Dijk .1978. "Toward a Model of Text Comprehension and Production”. Psychological Review, 85: 363- 394

Kintsch, Walter. 1998. Comprehension. A Paradigm for Cognition. Cambridge: Cambridge University Press.

Lipton, Peter. 2004. Inference to the Best Explanation, 2nd ed., London and New York: Routledge.

Livingston, Paisley. 1993. "Why Realism Matters: Literary Knowledge and the Philosophy of Science", In Realism and Representation: Essays on the Problem of Realism in Relation to Science, Literature, and Culture. Ed. George Levine, 134-154. Madison: University of Wisconsin Press. 
MacFie, Alec. 1971. “The Invisible Hand of Jupiter”. Journal of the History of Ideas 32: 595599.

Mantzavinos, C. 2001. Individuals, Institutions, and Markets. Cambridge: Cambridge University Press.

Mantzavinos, C. 2005. Naturalistic Hermeneutics. Cambridge: Cambridge University Press.

Mantzavinos, C. (ed.) 2009. Philosophy of the Social Sciences. Cambridge: Cambridge University Press.

Mantzavinos, C. 2012. "Explanations of Meaningful Actions". Philosophy of the Social Sciences, vol. 42, pp. 224-238.

Mantzavinos, C. 2013. “Explanatory Games”. Journal of Philosophy, vol. CX, pp. 606-632.

Mantzavinos, C. 2014. Explanatory Pluralism. Unpublished book manuscript.

Mantzavinos, C. (2015). Scientific Explanation, in: International Encyclopedia of the Social and Behavioral Sciences, 2nd. ed., Elsevier (forthcoming).

Nehamas, Alexander. 1981. "The Postulated Author: Critical Monism as a Regulative Ideal”, in: Critical Inquiry, vol. 8, pp. 133-149. 
Park, Suck-Jung. 2004. "Hypothetico-Deductivism is Still Hopeless". Erkenntnis 60: 229-234.

Popper, Karl. 1959/2003. The Logic of Scientific Discovery. London and New York: Routledge.

Popper, Karl. 1963/1989. Conjectures and Refutations, 5th Edition. London: Routledge.

Quine, Willard van Ormen. 1960. Word and Object. Cambridge/Mass. The MIT Press.

Rescher, Nicholas. 1997. Objectivity. The Obligations of Impersonal Reason. Notre Dame and London: University Notre Dame Press.

Rothschild, Emma. 1994. "Adam Smith and the Invisible Hand”. American Economic Review (Papers and Proceedings) 84: 319-322.

Rothschild, Emma. 2002. Economic Sentiments. Cambridge, MA.: Harvard University Press.

Schleiermacher, Friedrich Daniel Ernst (1999): Hermeneutik und Kritik. Mit einem Anhang sprachphilosophischer Texte Schleiermachers, herausgegeben und eingeleitet von Manfred Frank, 7. Auflage, Frankfurt am Main: Suhrkamp.

Scholz, Oliver R. 2001. Verstehen und Rationalität. $2^{\text {nd }}$ ed. Frankfurt am Main: Vittorio Klostermann. 
Scholz, Oliver R. 2004. "Die Idee einer Allgemeinen Hermeneutik - Vergangenheit und Zukunft“. (ed.) Neschke-Hentschke, Ada: Les Herméneutiques au Seuil du XXIème Siecle. Évolution et Débat Actuel. Louvain-Paris: Editions Peeters, 141-169.

Schloz, Oliver R. 2009. "The Methodology of Presumption Rules - Between the A Priori and the A Posteriori". (eds.) Kompa Nikola, Christian Nimtz and Christian Suhm: The A Priori and its Role in Philosophy. Paderborn: Mentis: 173-184.

Scholz, Oliver R. 2014. "Texte interpretieren - Daten, Hypothesen und Methoden", in: Borkowski, Jan, Descher, Jan, Ferder, Felicitas, Heine, Philipp David (eds.): Literatur interpretieren, Münster: Mentis (forthcoming).

Schurz, Gerhard (2014): Philosophy of Science. A Unified Approach, London and New York: Routledge.

Smith, Adam. 1759/1976. The Theory of Moral Sentiments. Oxford: Oxford University Press.

Smith, Adam. 1776/1976. An Inquiry Into the Nature and Causes of the Wealth of Nations. ed. Edwin Cannan. Chicago: The University of Chicago Press.

Smith, Adam. 1759/1980. Essays in Philosophical Subjects. Oxford: Oxford University Press.

Schmidt, Siegfried. 2000. “Interpretation: The Story Does Have an Ending”. Poetics Today 21: 621-632. 
Sinclair, Robert. 2002. "What is Radical Interpretation? Davidson, Fodor, and the Naturalization of Philosophy”. Inquiry 45: 161- 184. 